\title{
Comparative studies of the preference for free vs response-produced reinforcers
}

\author{
ROBERT W. POWELL* \\ University of South Florida, Tampa, Florida 33620
}

\begin{abstract}
Neither domesticated hooded rats nor wild black rats responded appreciably for water on a CRF schedule when free water was available. However, four out of five crows showed substantial responding for food in the presence of identical free food. Previous reports also indicate that type of reinforcer and species are variables which significantly influence this phenomenon. Nevertheless, the overall findings seem to be amenable to an explanation based upon incentive-motivation theory.
\end{abstract}

Jensen (1963) was the first to report that animals which had been trained to leverpress for food would continue to do so in the presence of identical free food. He further observed that pressing in the presence of free food was an exponential function of the number of rewarded prechoice responses. Interest in this phenomenon has increased recently, and Jensen's basic finding has been replicated a number of times (Carder \& Berkowitz, 1970; Neuringer, 1969, 1970; Sawisch \& Denny, 1973). While there have been a number of experiments in which the animals ate substantially more of the free food than the response-produced food (Atnip \& Hothersall, 1973; Hothersall, Huey, \& Thatcher, 1973; Koffer \& Coulson, 1971; Taylor, 1972), an explanation of these results is found in a study by Tarte and Snyder (1973), in which the authors manipulated the amount of leverpress vs free-food training prior to preference testing. When leverpress training was more extended, the animals obtained the major portion of their food through responding. However, when either the training time or the number of pellets obtained was equalized under the two procedures, the animals preferred the freely available food. Thus, it appears that prechoice training is perhaps the most critical factor in this phenomenon, a finding which essentially agrees with Jensen's (1963) original results.

Another relevant factor may be the value (quality or quantity) of the reinforcer. Taylor (1972) found that rats consistently obtained a larger percentage of their total daily intake of food than water through responding, even though they consumed more of the freely available reinforcers in both cases. Similarly, Carder (1972) observed that, when the reinforcer was a $10 \%$ sucrose solution, rats obtained $83 \%$ of their total consumption through responding, but when water was the reinforcer, only $26 \%$ was obtained through responding.

Species variables may also be important. Successful demonstrations of the preference for response-produced food have employed either domesticated rats or pigeons

*Reprints may be obtained from the author, Department of Psychology, University of South Florida, Tampa, Florida 33620. as Ss. In the only experiment which has extended this research to another species, Koffer and Coulson (1971) found that cats ate all of the freely available food before making any responses to obtain food. And while the phenomenon may be weak or absent in felines, a recent experiment by Sawisch and Denny (1973) suggests that it may be particularly powerful in birds. They showed that free-food eating could either be increased by making availability of the response key contingent upon it or decreased when availability of the key depended on not eating the free food (a DRO schedule).

It seems noteworthy that, even though a number of experiments have shown that animals prefer the freely available food, in all cases except Koffer and Coulson's (1971) study with cats, the animals continue to make some responses in order to obtain food. The pertinent theoretical question is why animals respond at all when they can obtain the same food without responding? Since there is no longer any question concerning the basic authenticity of this phenomenon, the present study was undertaken to assess its power and generality through the use of nondomesticated animals, namely, black rats and crows.

A problem one encounters in attempting to compare the results of previous experiments in this area is that Es have sometimes reported their results in terms of responses (Neuringer, 1969, 1970), proportional amounts of food eaten (Carder \& Berkowitz, 1970; Taylor, 1972), or latency to eat free vs earned food (Koffer \& Coulson, 1971), and clearly these dependent measures are not equivalent. Since any tendency to respond for food in the presence of free food is of interest, it would seem desirable that all reports include response measures as well as the amount of both the free and the earned reinforcer that is consumed.

\section{EXPERIMENT I}

\section{Method \\ Subjects. Two male and two female black rats (Rattus rattus) and two female and one male hooded rats (Long-Evans strain) were used. The black rats were first generation offspring of}


Table 1

Individual and Group Means of Reinforcements and Volume of Water Consumed with Free Water Absent Plus the Volume of Free Water Consumed When It Was Present

\begin{tabular}{|c|c|c|c|c|c|c|c|}
\hline \multirow[b]{2}{*}{ Ss } & \multicolumn{3}{|c|}{ Free Water Absent } & \multicolumn{4}{|c|}{ Free Water Present } \\
\hline & Sessions & $\begin{array}{c}\text { Reinforce- } \\
\text { ments }\end{array}$ & $\begin{array}{c}\text { Earned } \\
\text { Water }(\mathrm{mL})\end{array}$ & Sessions & $\begin{array}{l}\text { Reinforce- } \\
\text { ments }\end{array}$ & $\begin{array}{c}\text { Earned } \\
\text { Water }(\mathrm{mL})\end{array}$ & $\begin{array}{c}\text { Free } \\
\text { Water }(\mathrm{mL})\end{array}$ \\
\hline & & & & Hooded Rats & & & \\
\hline HR-6 & 16 & 369 & 9.4 & 16 & 7 & 0.3 & 22.9 \\
\hline HR-10 & 16 & 355 & 9.5 & 17 & 18 & 0.6 & 20.6 \\
\hline HR-11 & 14 & 418 & 10.4 & 13 & 21 & 0.6 & 22.6 \\
\hline \multirow[t]{2}{*}{ Mean } & 15.3 & 381 & 9.8 & 15.3 & 15.1 & 0.5 & 22.0 \\
\hline & & & . & Black Rats & & & \\
\hline BR-4 & 25 & 274 & 5.6 & 24 & 1 & 0.0 & 21.0 \\
\hline BR-22 & 27 & 285 & 6.1 & 23 & 0 & 0.0 & 19.6 \\
\hline BR-25 & 20 & 353 & 6.5 & 20 & 21 & 0.5 & 21.7 \\
\hline BR-26 & 20 & 263 & 6.0 & 22 & 7 & 0.2 & 22.0 \\
\hline Mean & 23 & 294 & 6.1 & 22.3 & 7.3 & 0.2 & 21.1 \\
\hline
\end{tabular}

field-trapped animals. Black rats are members of the family Muridae (Old World rats and mice), which also includes the Norway rat (Rattus norwegicus). It is generally believed that domestic rat strains were all developed from Rattus norwegicus stock (Barnett, 1963). All rats were experimentally naive and were between 4 and 6 months of age at the start of the experiment. The animals were housed in individual cages with free access to Purina Lab Chow.

Apparatus A Lehigh Valley Electronics rat test chamber, Model 1417, was used. A bank of three 28-V dc lights, located $30 \mathrm{~mm}$ above the lever, came on each time the dipper was presented, thus providing a stimulus indicating availability of the reinforcer. The time of dipper presentation was $5.0 \mathrm{sec}$. The free water was provided by means of a conventional bottle and drinking spout of the same type as that attached to each rat's home cage. The spout was inserted through an opening in one of the Plexiglas walls of the test chamber $50 \mathrm{~mm}$ above the grid floor and protruded $10 \mathrm{~mm}$ into the chamber, so that the bottle and the spout were clearly visible to the animal.

Procedure. The deprivation procedure consisted of limiting the rats to $5 \mathrm{~min}$ access to water in their home cages after each session. Thus, the rats were on a water-deprivation schedule of approximately $23 \mathrm{~h}$. Each rat was first exposed to automatic dipper presentations until it drank reliably. Next the animals were shaped through the method of successive approximation and were trained under a continuous reinforcement schedule (CRF), in which each response is reinforced. This continued until responding was stable over five consecutive sessions. Then the rats were tested with free water present for five consecutive sessions and with water absent for five sessions. Testing continued in subsequent sessions with free water either present or absent on an unsystematic schedule. The amount of earned water and free water consumed was measured in each session. Experimental sessions were $60 \mathrm{~min}$ per day.

\section{Results and Discussion}

The complete results, which are presented in Table 1, show that both species made few responses and drank large amounts of the free water when it was present. All rats made a large number of responses to obtain water with free water absent. However, the amount of water obtained through responding when free water was absent was less than half the amount consumed during free-water sessions. Number of reinforcements obtained is presented instead of number of responses, because several of the rats made multiple responses per reinforcement. It is interesting to note that the black rats obtained approximately $40 \%$ less water through responding than the hooded rats with free water absent, but both species consumed nearly the same volume during the free-water sessions.

The present results replicate the findings of Taylor (1972) and Carder (1972) relative to minimal responding for water with the free water present. Thus, there is consistent evidence that animals will respond much more for food than for water when the two commodities are freely available. This conforms to the general observation that food is a more effective reinforcer than water, although most species can tolerate much longer periods of food deprivation than of water deprivation. The former observation was empirically verified by Fallon, Thompson, and Schild (1965), who showed that with equal deprivation times and equal reinforcement weights, rats responded twice as rapidly for food as for water.

It is also possible that the differences in responding for food vs water may relate to differences in amount of reward per response (response cost), but the available reports do not provide sufficient information to evaluate this conjecture.

\section{EXPERIMENT II}

As noted earlier, pigeons seem to have a strong preference for response-produced food over free food. Therefore, it seemed worthwhile to see if this phenomenon extended to a nondomesticated avian species, the crow. Crows were chosen because they can be trained reliably to keypeck for food (Powell, 1973), develop response patterns similar to those of pigeons under intermittent schedules of reinforcement (Powell, 1972), but adjust their responding more readily to the prevailing contingencies than pigeons (Powell, 1974).

This experiment also studied the effect of location of the free food within the test chamber (adjacent to the food hopper vs remote). 


\section{Method}

Subjects. Five adult common crows (Corvus brachyrhynchos), approximately 12 to 18 months of age at the start of the experiment, were used. The birds were maintained at approximately $80 \%$ of their free-feeding weight during the experiment. All of the crows had several months of training under a CRF schedule prior to the experiment. The crows were housed in individual cages where they had free access to water and grit.

Apparatus. A Lehigh Valley pigeon test chamber, Model 1519C, which had been modified for crows as described earlier (Powell, 1973), was used. A circular glass vessel $5 \mathrm{~cm}$ high, with a diam of $12 \mathrm{~cm}$ and weighing $300 \mathrm{~g}$, was used as the free-food dish. The weight and design of this vessel prevented it from being tipped over by the crows.

Procedure. The crows were given additional training under a CRF schedule until responding was stable over five consecutive sessions. Reinforcement time was $2.0 \mathrm{sec}$. Then the crows were tested with free food present for five sessions and with free food absent for five sessions. Testing continued in subsequent sessions with free food either present or absent on an unsystematic schedule. Top Choice, a processed meat substitute dog food, was used. Fifty grams of this food was available in the food hopper and in the free-food dish when called for by the experimental schedule. The amount consumed was determined by postsession measurements of the amount remaining in both the food hopper and the free-food dish. In addition, the location of the free-food dish within the test chamber was changed for four (Ss 6, 8, 11, and 12) of the five crows midway through the experiment. For these crows, the dish was removed from a location adjacent to the rear wall of the test chamber (relative to the response panel) to a position adjacent to the food hopper. In the latter position the edge of the dish was approximately $3 \mathrm{~cm}$ from the opening to the food hopper. Experimental sessions were $30 \mathrm{~min}$ per day.

\section{Results and Discussion}

All of the crows except $\mathrm{C}-1$ continued to respond frequently for food in the presence of free food, as shown in Table 2. Thus, four of the crows maintained response rates in the presence of free food that ranged from approximately 50\% (C-6) to 75\% (C-11) of their rates when free food was not present. These results would not warrant a statement that the crows "preferred" either free or response-produced food, but they clearly show that substantial responding was maintained when the animal could have obtained far more than it normally consumed without responding. So these results do extend the generality of the

Table 2

Individual and Group Means of Responses and Amount of Food Consumed With Free Food Absent Plus the Amount of Free Food Consumed When It Was Present

\begin{tabular}{|c|c|c|c|c|c|c|c|}
\hline \multirow[b]{2}{*}{ Ss } & \multicolumn{3}{|c|}{ Free Food Absent } & \multicolumn{4}{|c|}{ Free Food Present } \\
\hline & $\begin{array}{l}\text { Ses- } \\
\text { sions }\end{array}$ & $\mathbf{R}^{*}$ & $\begin{array}{c}\text { Earned } \\
\text { Food } \\
\text { (g) }\end{array}$ & $\begin{array}{l}\text { Ses- } \\
\text { sions }\end{array}$ & $\mathrm{R}^{*}$ & $\begin{array}{c}\text { Earned } \\
\text { Food } \\
(\mathrm{g})\end{array}$ & $\begin{array}{c}\text { Free } \\
\text { Food } \\
(\mathrm{g})\end{array}$ \\
\hline C-1 & 17 & 52.6 & 16.8 & 16 & 6.8 & 2.6 & 16.8 \\
\hline C-6 & 26 & 121.4 & 14.3 & 28 & 56.5 & 7.1 & 7.7 \\
\hline C-8 & 21 & 76.9 & 12.4 & 24 & 47.6 & 6.8 & 6.8 \\
\hline C-11 & 15 & 104.7 & 21.9 & 18 & 79.2 & 16.8 & 1.3 \\
\hline$C-12$ & 17 & 53.8 & 11.0 & 28 & 37.2 & 6.1 & 5.2 \\
\hline Group $\bar{X}$ & 19.2 & 81.9 & 15.3 & 22.8 & 45.5 & 7.9 & 7.6 \\
\hline
\end{tabular}

*Responses
Table 3

Mean Number of Responses and Amount of Free Food and Response-Produced Food Consumed With the Free-Food Dish in a Remote Corner or Adjacent to the Food Hopper

\begin{tabular}{lccc}
\hline & \multicolumn{3}{c}{ Free Food "Remote" } \\
\cline { 2 - 4 } Ss & Responses & $\begin{array}{c}\text { Earned } \\
\text { Food }(\mathrm{g})\end{array}$ & $\begin{array}{c}\text { Free } \\
\text { Food }(\mathrm{g})\end{array}$ \\
\hline C-6 & 34.5 & 5.7 & 6.5 \\
C-8 & 38.8 & 6.6 & 8.3 \\
C-11 & 76.4 & 17.8 & 1.2 \\
C-12 & 49.9 & 7.8 & 3.3 \\
Group $\bar{X}$ & 49.9 & 9.5 & 4.8 \\
& & Free Food “Adjacent" & \\
C-6 & 90.5 & 9.3 & 9.5 \\
C-8 & 52.8 & 7.0 & 5.9 \\
C-11 & 80.2 & 16.4 & 1.4 \\
C-12 & 22.5 & 4.1 & 7.4 \\
Group $\bar{X}$ & 61.5 & 9.2 & 6.1 \\
\hline
\end{tabular}

phenomenon under consideration.

Table 3 shows that the location of the free-food dish had little effect upon the tendency to respond for food. When the dish was adjacent to the food hopper, the crows actually responded somewhat more frequently to obtain food (except for C-12), although they ate slightly more of the free food. Hothersall et al (1973) also found that the method of free-food presentation had little effect, but most of their rats consumed more free food than response-produced food.

While the present phenomenon has sparked considerable experimental interest, there have been few attempts to integrate this effect into existing theory. Neuringer (1970) concluded simply that instrumental responses (responses which produce food) can serve as their own motivation and reward. Bolles (1972) has recently cited evidence from a number of sources that seem to offer support for an incentive-motivation theory of instrumental conditioning based upon contiguity while deemphasizing the importance of response strengthening through reinforcement. The autoshaping phenomenon is an example of this. Under this procedure, a stimulus and a reinforcer are presented successively in repeated pairings, with no response contingency in effect. Both pigeons (Brown \& Jenkins, 1968) and quail (Gardner, 1969) develop considerable responding in the presence of the stimulus (white keylight) which precedes the reinforcer (food). Bolles offers an explanation of this and similar findings on the basis of a "law of prior expectancies." This law states that an animal will have either learned or innate R-S expectancies, e.g., throughout the life of the pigeon, food and pecking have been associated. Therefore, the presentation of food engenders pecking, even though present environmental circumstances do not require it.

The phenomenon studied here appears analogous to this effect, in that responding is maintained in the absence of any requirement for it. Response-independent food is available at all times 
under this procedure, while it is presented periodically under autoshaping. Thus, there appear to be two sources for an associative explanation of the behavior in question: (1) the association between the response and food, where the response mimics the consummatory behavior of the animals, as with pecking in pigeons and other birds, and (2) where the response has been associated with food on the basis of a contingency, as in operant conditioning. Such an explanation would predict more frequent instrumental responding in the presence of free food for birds than rats, as both associative factors would operate for birds but only the latter for rats. Neuringer's (1969) findings and the present results support this prediction.

There have been two recent experiments that suggest new perspectives on the present phenomenon. Wallace, Osborne, Norborg, and Fantino (1973) found that changes in ambient stimulus conditions which accompanied entries into a food source influenced the source the pigeons chose. However, the data in this report were so equivocal that the effect indicated would appear to be very weak. For example, in their second experiment there were three dependent variables, but the change in stimulation affected only one of these. Mitchell, Scott, and Williams (1973) found that familiarity with the free-food container influenced the amount of food eaten. They suggest that laboratory rats are somewhat neophobic. This factor appears to have had no effect in the present experiment, however, as both species of rats drank large volumes of free water as soon as it was introduced.

In conclusion, the now consistent observation that animals respond for food in the presence of identical free food appears to favor an incentive-motivation explanation based upon contiguity, in preference to response strengthening through reinforcement. However, this latter factor is not without influence, as shown by the effect that amount of training has upon behavior in this situation (Jensen, 1963; Tarte \& Snyder, 1973). The failure of animals to respond for water under these conditions apparently relates to the value of the incentive (amount of reward), which is a central factor in contemporary incentive-motivation theory (Spence,
1956). So, the latter findings can be reconciled with this theory.

\section{REFERENCES}

Atnip, G., \& Hothersall, D. The preference of albino rats for free or response-produced food. Bulletin of the Psychonomic Society, 1973, 2, 153-154.

Barnett, S. A. The rat. Chicago: Aldine, 1963.

Bolles, R. C. Reinforcement, expectancy, and learning. Psychological Review, 1972, 79, 394-409.

Brown, P. L., \& Jenkins, H. M. Auto-shaping of the pigeon's key-peck. Journal of the Experimental Analysis of Behavior, 1968, 11, 1-8.

Carder, B. Rats' preference for earned in comparison with free liquid reinforcers. Psychonomic Science, 1972, 26, 25-26.

Carder, B., \& Berkowitz, K. Rat's preference for earned in comparison with free food. Science, 1970, 167, 1273-1274.

Fallon, D., Thompson, D. M., \& Schild, M. E. Concurrent food and water reinforced responding under food, water, and food and water deprivation. Psychological Reports, 1965, 16, $1305-1311$.

Gardner, W. M. Auto-shaping in bobwhite quail. Journal of the Experimental Analysis of Behavior, 1969, 12, 279-281.

Hothersall, D., Huey, D., \& Thatcher, K. The preference of rats for free or response-produced food. Animal Learning \& Behavior, 1973, 4, 241-243.

Jensen, G. D. Preference for bar pressing over "free loading" as a function of number of rewarded presses. Journal of Experimental Psychology, 1963, 65, 451-454.

Koffer, K., \& Coulson, G. Feline indolence: Cats prefer free to response-produced food. Psychonomic Science, 1971, 24, 41-42.

Mitchell, D., Scott, W. D., \& Williams, K, D. Container neophobia and the rat's preference for earned food. Behavioral Biology, 1973, 9, 613-624.

Neuringer, A. J. Animals respond for food in the presence of free food. Science, $1969,166,399-401$.

Neuringer, A. J. Many responses for food reward with free food present. Science, 1970, 169, 503-504.

Powell, R. W. Responding under basic schedules of reinforcement in the crow. Journal of Comparative \& Physiological Psy chology, 1972, 79, 156-164.

Powell, R. W. Operant responding in the common crow (Corvus brachyrhynchos). Bulletin of the Psychonomic Society, 1973, 1, 401-403.

Powell, R. W. Comparison of DRL responding in pigeons and crows. Journal of Comparative \& Physiological Psychology, 1974 , in press.

Sawisch, L. P. \& Denny, M. R. Reversing the reinforcement contingencies of eating and keypecking behaviors. Animal Learning \& Behavior, 1973, 1, 189-192.

Spence, $\mathbf{K}$. W. Behavior theory and conditioning. New Haven: Yale University Press, 1956.

Tarte, R. D., \& Snyder, R. L. Some sources of variation in the barpressing vs freeloading phenomenon in rats. Journal of Comparative \& Phy siological Psychology, 1973, 84, 128-133.

Taylor, G. T. A limitation of the contrafreeloading phenomenon. Psychonomic Science, 1972, 29, 173-174.

Wallace, R. F., Osborne, S., Norborg, J., \& Fantino, E. Stimulus change contemporaneous with food presentation maintains responding in the presence of free food. Science, 1973, 182, 1038-1039.

(Received for publication January 11, 1974; revision received April 8, 1974.) 